\title{
AS RELAÇÕES DE TRABALHO E GÊNERO FEMININO
}

\section{ARTIGO ORIGINAL}

SILVA, Cristiane Rosana $\mathrm{Da}^{1}$

SILVA, Cristiane Rosana Da. As relações de trabalho e gênero feminino. Revista Científica Multidisciplinar Núcleo do Conhecimento. Ano 04, Ed. 08, Vol. 01, pp. 3652. Agosto de 2019. ISSN: 2448-0959

\section{RESUMO}

Em princípio, é pertinente mencionar que a industrialização foi o marco para o surgimento do direito do trabalho. Antes da revolução industrial, que impôs definitivamente a separação entre capital e trabalho, não se pensava em direito do trabalho. Foram as miseráveis condições a que se viram lançadas os trabalhadores, nos primórdios da industrialização, que os levaram a se unir e a reivindicar direitos, quebrando assim o paradigma de que o contrato de locação do trabalho era como qualquer outro contrato regido pelas leis de oferta e procura do mercado. Ressalta-se que se as condições de trabalho e ausência de garantia de direitos já eram duras para os homens, pior ainda era a situação das mulheres que trabalhavam, pois seu serviço sofria duplo preconceito: primeiro o biológico, pelas diferenças físicas existentes entre os sexos, cuja maior delas é a maternidade; e segundo, o social, no qual o trabalho feminino era visto como inferior ao masculino e, portanto, de menor valor. Assim o trabalho das mulheres é um capítulo à parte na história do direito do trabalho, sendo ele construído à margem do direito trabalhista. É pertinente destacar que ao longo dos anos, com o advento da Consolidação das Leis do Trabalho (CLT), das Constituições Federais e de outras normas legais, a mulher começou a ter um espaço maior perante a sociedade, despontando em cargos de destaque em várias esferas: privada, pública, política. Tudo isso demonstra a importância e a dignificação da condição de ser mulher

1 Bacharelada em Direito pelo Centro Universitário de Várzea Grande-MT. Licenciatura plena em Pedagogia pela FANAN - Faculdade De Nanuque. 
e de poder contribuir para o engrandecimento familiar e profissional. Fica claro que, antes do exercício de qualquer função como dona de casa, esposa, mãe, filha e empregada, tanto do setor público quanto privado, é a condição de ser mulher, com seus direitos e obrigações, que sempre prevalecerá.

Palavras-Chave: Industrialização, condições de trabalho, garantia de direitos, trabalho das mulheres.

\section{INTRODUÇÃO}

Em princípio, concerne mencionar que ninguém pode pretender estudar e entender o Direito do Trabalho sem conhecer a sua origem e sua evolução histórica, mesmo que de forma superficial, sob pena de incorrer em equívocos jurídicos e sociais inaceitáveis para um operador do direito.

Conhecendo o passado, evita-se repetir no presente e no futuro os mesmos erros que levaram ao sofrimento e até por vezes a morte de milhões de pessoas, vítimas da necessidade do lucro sem limite e da falta de solidariedade social dos que ignoram a dimensão humana do trabalho inserto no processo de produção.

Assim, tratando-se de um resumo, evidentemente que este texto introdutório não será suficiente para permitir aos que tiverem acesso a este artigo, o pleno conhecimento sobre os fatos econômicos e sociais que deram origem ao Direito do Trabalho e ditaram a sua evolução, acredita-se que servirá apenas para a necessária contextualização inicial dos que estudam o tema. Portanto, é recomendado e se destaca com suma importância a leitura das obras aqui mencionadas, posto que os autores se aprofundam nos temas que serão descritos no presente artigo.

Por introdução é pertinente ressaltar que se houvesse, no mundo fático, a igualdade real de classes, não haveria, a princípio, sequer a necessidade de uma ramificação de direitos distintos entre o gênero humano. A diferenciação dos direitos do trabalho da mulher persiste exatamente por conta da existência de diferenças e da luta entre 
as classes, iniciada há muitos anos e que infelizmente ainda prevalece no mundo atual.

Por mais que haja luta pela igualdade entre os gêneros no mercado de trabalho, é incontestável que a mulher necessita de um amparo legal maior, e não se trata de preconceito ou discriminação, mas de uma adequação à estrutura física e psíquica da mulher. Daí a necessidade de uma legislação diferencial, que as ampare em seus direitos.

\section{A EVOLUÇÃO DO DIREITO TRABALHISTA}

Em princípio, é pertinente mencionar os ensinamentos de Gomes e Gotsschalk (2005):

O trabalho é tão antigo quanto o homem que começou a trabalhar pela necessidade de satisfazer a fome e assegurar a defesa pessoal. A mão foi o seu primeiro instrumento de trabalho e, por isso, o homem primitivo tinha horizonte limitado. Quando a sua mão foi prolongada pelo uso de utensílios, o homem se posicionou acima dos outros animais e adquiriram maiores condições de sobrevivência e de atendimento as suas necessidades (GOMES; GOTSSCHALK, 2005, p. 29).

Concernente mencionar que na sua existência o homem trabalhou livre, em benefício próprio ou de seu grupo, trabalhou como escravo, servo e empregado, por conta e em benefício de outrem.

\section{DA ESCRAVIDÃO}

Ressalta-se que de certa forma, a escravidão significou um imenso progresso da humanidade, pode até parecer um paradoxo tal afirmação, porém a escravidão sucedeu à antropofagia ou à imolação dos prisioneiros. Sussekind (2003) preceitua que, 
Os combates entre tribos ou entre grupos, os vencedores executam os vencidos sobreviventes para comê-los ou para se livrarem de incômodos que ainda podiam provocar. Posteriormente concluíram que em vez de liquidarem os prisioneiros, era mais útil escravizá-los para gozar de seu trabalho (SUSSEKIND, 2003, p. 29-31).

No regime da escravidão, o trabalho era forçado e seus frutos eram exclusivamente voltados ao dono do escravo. Estes por sua vez tinham como recompensa somente a alimentação e moradia.

Ainda mencionando Sussekind (2003), ele nos ensina:

A escravidão, entre os gregos e os romanos atingiu grandes proporções. $\mathrm{Na}$ Grécia havia fábricas de flautas, de facas, de ferramentas agrícolas e de móveis, onde o operário era todo composto de escravos. Em Roma os grandes senhores tinham escravos de várias classes, desde os pastores até gladiadores, músicos, filósofos e poetas. Quando desses escravos ganhavam a liberdade, por diversos motivos, o único direito que adquiriam era o de trabalhar nos seus ofícios habituais ou alugandose a terceiros mediante salários. Constituindo-se nos primeiros trabalhadores assalariados da história (SUSSEKIND, 2003, p. 30).

\section{REGIME DE SERVIDÃO}

Ressaltando os ensinamentos de Nascimento (2003), o mesmo ressalta que:

Os servos, apesar de não serem considerados escravos, não tinham liberdade, estavam ligados às glebas dos senhores feudais e não podiam locomover-se para outras terras. A base dessa relação estava na posse da terra pelos senhores, que se tornavam os possuidores de todos os direitos, numa economia que se firmava na terra - agricultura ou pecuária (NASCIMENTO, 2003, p. 41). 
Modificou-se a forma como o trabalhador era enxergado; enquanto o escravo era coisa, objeto de direito, o servo já era visto como pessoa, com capacidade de ser sujeito de relações jurídicas limitadas, ligadas às terras. Os cervos tinham o direito de herança de animais, objetos pessoais e às vezes de uso de pastos.

\section{CORPORAÇÕES DE OFÍCIO}

$\mathrm{Na}$ idade média, o aumento dos clientes exigiu do artesão, até então livres e autônomos, a contratação de auxiliares, para aprenderem o ofício e trabalharem sobre suas ordens. Após o fim do tempo de aprendizagem, os aprendizes passavam a condição de companheiros e eram assalariados pelos mestres.

Neste sentido Nascimento (2003) preceitua que:

O trabalho profissional só podia ser exercido pelos membros da Corporação, que tinha número limitado de membros. O trabalho tinha que passar obrigatoriamente pelas fases corporativas, ou seja, como aprendiz, como companheiro e, como mestre, que era a hierarquia na profissão (NASCIMENTO, 2003, p. 43).

Ainda mencionando o autor, percebemos que "as Corporações de Ofício regulavam a produção e as condições de trabalho, investidas de um rigoroso monopólio na fabricação, venda e regulamentação dos produtos e do mercado. As corporações eram integradas por mestres, companheiros e aprendizes. Os mestres consubstanciavam o grau mais elevado na escala hierárquica" (NASCIMENTO, 2003, p. 45).

Destaca-se que os aprendizes eram admitidos e assumiam o compromisso de obediência total ao mestre, recebendo como pagamento, cama, comida, ensino do ofício e uma pequena retribuição fixada nos estatutos das corporações. Os companheiros eram os aprendizes que terminavam a etapa de aprendizagem e, quando não adquirindo qualidade de mestre, permaneciam na oficina como trabalhadores assalariados. 


\section{RELAÇÃO DE EMPREGO NA REVOLUÇÃO INDUSTRIAL}

Por ocasião da Revolução Industrial, na metade do século XVIII, surgiu o trabalho humano prestado pessoalmente em proveito de outrem e mediante retribuição como um dos elementos do processo de produção vigente. Foi esse novo tipo de trabalho, caracterizador da relação de emprego, que se constituiu mais tarde no objeto do Direito do Trabalho, ou melhor, das leis trabalhistas.

\subsection{ORIGEM DO DIREITO DO TRABALHO}

Neste sentido Gomes e Gottschalk (2005) afirmam que:

O Direito do Trabalho é de formação legislativa e científica recente, estando sua origem histórica vinculada à Revolução Industrial iniciada com a descoberta da máquina a vapor em 1712 por Thomas Newcomen e aperfeiçoada na metade do século XVIII por James Wall, que levou à aceleração do processo de industrialização da economia, servindo ela, a máquina a vapor, como fonte de energia para mover as pesadas máquinas já inventadas para a indústria têxtil (GOMES; GOTTSCHALK 2005, p. 1).

Nesta baila, Rodrigues Pinto (2002) também assevera que:

O trabalho humano e suas repercussões sociais são tão velhas quanto os primeiros impulsos de civilizações oriundas do racionalismo. Todavia, a relação do trabalho humano prestado pessoalmente em proveito de outrem e retribuído como forma sistemática de utilização da energia produtiva só foi, realmente, proporcionada pelo advento da chamada Revolução Industrial (PINTO, 2002, p. 22). 


\section{INFLUÊNCIA DA REVOLUÇÃO INDUSTRIAL NO SURGIMENTO DO DIREITO DO TRABALHO}

Passaremos a discutir a importância da Revolução Industrial para o surgimento da proteção das relações trabalhistas. Claramente, podemos estar descrevendo que é algo embrionário para a proteção do trabalho, mas que ainda sim referenciado como um marco desse ponto. Ainda mencionando Rodrigues Pinto (2002), ele nos preceitua que:

O Direito do Trabalho é fruto da inteiração do fato econômico com a questão social, catalisados pela Revolução Industrial. Segundo ele, a produção em larga escala exigiu a concentração de trabalhadores, antes dispersos nos pequenos núcleos artesanais e nas atividades agrárias, em torno das unidades onde se instalaram as máquinas, o que importou na urbanização da sociedade industrial. Essa aglutinação facilitou a intercomunicação entre os trabalhadores e despertou neles uma consciência de classe (PINTO, 2002, p. 22).

O surgimento da consciência coletiva em relação às péssimas condições de trabalho a que eram submetidos, sintetizadas nos baixos salários, na submissão a jornadas de trabalho extenuantes, na falta de proteção contra acidentes do trabalho e na impossibilidade de lazer, fez com que os trabalhadores concluíssem que não eram destinatários dos benefícios gerados pelo aumento da produção de bens e desenvolvimento tecnológico, resultando nas primeiras reivindicações trabalhistas. A discussão sobre a repercussão social da transformação econômica das relações de trabalho ficou conhecida como questão social.

\section{APARECIMENTO DA OIT - ORGANIZAÇÃO INTERNACIONAL DO TRABALHO}

Com o fim da Primeira Guerra Mundial, que durou o período de 1914 a 1918, a Liga das Nações firmou o Tratado de Versalhes, que trouxe consigo, dentre outros assuntos, nove princípios gerais relativos à regulamentação do trabalho nos países 
signatários, cuidando da duração diária e semanal da jornada de trabalho, dos repousos do trabalhador, do direito de associação e outras matérias dessa natureza. Esses princípios foram absolvidos pela legislação dos países industrializados ou em processo de industrialização.

Neste sentido Sussekind (2003) nos ensina que:

Para fomentar a execução dos princípios do Tratado de Versalhes relativos às relações de trabalho, a Liga das Nações instituiu, como uma de suas agências de inter-relações dos povos, a Organização Internacional do Trabalho - OIT, que continuou existindo e desempenhando a função de buscar a evolução das condições de trabalho e da democracia nas relações laborais no mundo, apesar da extinção posterior da Liga das Nações, e hoje está integrada à estrutura da ONU (SUSSEKIND, 2003, p.29-31).

\section{A EVOLUÇÃO DO DIREITO DO TRABALHO NO BRASIL}

Em princípio é importante mencionar que no Brasil, o Direito do Trabalho originou-se de forma diferente do resto do mundo. Enquanto, em outros países, a produção significativa de normas trabalhistas decorreu de fontes autônomas, convenções e acordos coletivos de trabalho, no Brasil a produção das normas trabalhistas em sua quase totalidade deveu-se às fontes heterônomas.

Ressalta-se que antes da formação de uma consciência de classe plena, o que daria aos trabalhadores a força coletiva, elemento essencial de uma atuação reivindicatória de sucesso, o Estado positivou leis regulamentando minuciosamente todas as condições de trabalho na empresa, garantindo aos trabalhadores o que havia de melhor e mais avançado no mundo do trabalho até o presente momento.

Neste sentido Rodrigues Pinto (2002) ressalta que:

Se o Direito do Trabalho surgiu da força coletiva dos trabalhadores, caracterizando-se como um direito de conquista, no Brasil ele começou 
pelo direito individual, sendo outorgado pelo Estado. Por essas razões, entendemos peculiar o contexto político-social que dá suporte ao nosso ornamento jurídico trabalhista, fazendo fracassar as soluções importadas de outros sistemas jurídicos para resolver os nossos problemas relacionados ao conflito capital/trabalho (PINTO, 2002, p. 22).

Antes do trabalho com os elementos caracterizadores da relação de emprego, tivemos o trabalho escravo, o colonato e as corporações de ofício. Os escravos daqui tinham uma situação similar a de qualquer outro escravo em qualquer lugar do mundo. Diferentemente dos servos dos senhores feudais da Europa, tivemos no Brasil os colonos, que eram trabalhadores livres e ligados à terra pela figura jurídica do arrendamento de prédio rústico. Algumas corporações de ofício existiram no Brasil, mas não chegaram a possuir a influência e a importância de suas similares o estrangeiro.

\subsection{REVOLUÇÃO DE 1930}

Ressalta-se que apesar da expansão e do avanço da filosofia liberal no mundo, havia os que se opunham aos seus postulados e defendia a intervenção estatal nas relações sociais privadas como forma de garantir a efetiva liberdade dos contratantes, principalmente nas negociações sobre condições de trabalho do emprego, a parte economicamente fraca na relação de emprego, com o patronato.

Neste sentido, Gomes e Gottschalk (2005) compreendem que "os que eram contrários ao liberalismo e à omissão do Estado, pregavam o dirigismo contratual nas relações de trabalho e a limitação da esfera negocial das partes, posto que a plena liberdade de contratar tinha levado a classe trabalhadora a mais baixa condição de vida, a uma situação de miséria absoluta e sem precedentes para ela" (GOMES; GOTTSCHALK, 2005, p. 2)

É importante mencionar que com a Revolução de 1930 e a ascensão de Getulio Vargas ao poder, cujo direcionamento político era de oposição ao liberalismo e de defesa da intervenção do Estado na ordem econômica e social, para garantia do bem 
estar social, a ordem jurídica trabalhista foi profundamente alterada pela intensa produção legislativa e adquiriu a estrutura que até hoje rege as relações trabalhistas no Brasil, sendo inclusive o criador do Ministério do Trabalho.

\subsection{A CONSOLIDAÇÃO DAS LEIS DE TRABALHO}

Em 1ํ de maio de 1943, o Decreto-Lei $n^{\circ} 5.452$, assinado por Getúlio Vargas consolidou todas as leis sobre o Direito Individual, Coletivo e Processual do Trabalho então vigente. A conhecida CLT - Consolidação das Leis Trabalhistas vigentes até hoje, inseridas as modificações necessárias à compatibilidade dos seus preceitos às novidades ditadas pela dinâmica das relações de emprego e avanço econômico social.

\subsection{A CONSTITUIÇÃO DA JUSTIÇA DO TRABALHO}

A Justiça do Trabalho foi instituída pela Constituição da República de 1934 (BRASIL, 1934, artigo 122, § único) com caráter administrativo e composição partidária, posto que liga ao Poder Executivo e integrada por juízes classistas.

Ressalta-se, entretanto segundo Nascimento (2003) que:

Foi somente com a Constituição da República de 1946, a Justiça do trabalho passou a integrar a estrutura do Poder Judiciário. O Conselho nacional do Trabalho foi transformado no Tribunal Superior do Trabalho e os Conselhos Regionais em Tribunais Regionais do Trabalho. Criandose também a carreira da judicatura trabalhista, com todas as garantias da magistratura e ingresso mediante concurso público, com a manutenção dos juízes classistas, cujos mandados passaram para três anos (NASCIMENTO, 2003, p. 167-221). 


\subsection{A CONSTITUIÇÃO BRASILEIRA DE 1988 E A PROTEÇÃO AO TRABALHADOR}

Ressalta-se que de todas as Constituições que o Brasil já experimentou, foi a de 1988 que mais avançou no campo social, principalmente na área trabalhista. Segundo o seu artigo $1^{\circ}$ dentre os fundamentos de nossa República estão "os valores sociais do trabalho e da livre iniciativa" (BRASIL, 1988).

A Constituição Federal de 1988 garantiu o livre exercício de qualquer trabalho, ofício e profissão, atendida as qualificações profissionais estabelecidas em lei, e também teve a preocupação de conferir status constitucional aos direitos básicos dos trabalhadores, antes previstos apenas em normas infraconstitucionais, livrando-os das variações de humor do Poder Executivo, expressadas nas esferas medidas provisórias por ele editadas, bem como das maiorias ocasionais do Congresso Nacional não comprometidas com a Justiça Social.

Ressalta-se que os direitos que se encontram protegidos no texto constitucional e por isso modificáveis somente mediante processo legislativo especial, com quorum qualificado e 02 (dois) turnos de votação, os direitos trabalhistas enumerados nos 34 (trinta e quatro) incisos e 01 (um) parágrafo do artigo $7^{\circ}$ da Constituição de 1988 ficam mais resguardados (BRASIL, 1988).

\section{O DIREITO TRABALHISTA COM RELAÇÃO À MULHER}

De início é necessário realizar um breve relato histórico acerca do trabalho feminino e suas conquistas. Na época colonial, não há o que redigir sobre trabalho feminino que não fosse a da constituição da família e o simples objeto de posse, prazer masculino e procriação.

Segundo os ensinamentos de Nascimento (2003):

Já naquela época fazia-se aflorar a discriminação enraizada na esteriotipação das classes entre os sexos e dentro do próprio sexo 
feminino, tendo em vista que a mulher branca tinha função matrimonial e maternal, enquanto que as negras nativas contribuíam apenas com o corpo para a satisfação do prazer, dentro outras atividades de menor valor (NASCIMENTO, 2003, p. 167-221).

Ressalta-se que as camponesas, por exemplo, trabalhavam muito, pois tinham que cuidar das crianças, fiar a lã, tecer e ajudar a cultivar as terras. As mulheres com um nível social mais alto tinham uma rotina igualmente atribulada, pois administravam a gleba familiar quando seus maridos estavam fora. Também cabiam a essas mulheres 0 atendimento aos doentes e a educação das crianças.

Ainda mencionando o autor, o mesmo preceitua que "naquela época, as mulheres nunca podiam ocupar cargos de destaque. Elas eram sempre consideradas como aprendizes em todas as atividades que desenvolviam" (NASCIMENTO, 2003, p. 175).

Destaca-se que na época do Império, as mulheres continuavam sendo discriminadas, inclusive na constituição política sua existência era praticamente ignorada, não tendo sequer o direito ao voto, pois a maioria delas era analfabeta. Observa-se assim, que as mulheres eram completamente marginalizadas pelo Estado e viviam enclausuradas em seus lares. As solteiras auxiliavam a mãe nos afazeres domésticos, e as casadas acompanhavam os maridos, carregando seus pertences e thes servindo constantemente.

\subsection{O TRABALHO DA MULHER NA FASE REPUBLICANA}

O fim da escravidão representou um marco na história do direito do trabalho, pois a partir dele, novos postos foram criados, novos grupos foram homogeneizados e novas relações de trabalho foram implantadas.

Com a proclamação da república, houve uma revolução da mão-de-obra do país, tendo em vista as possibilidades de escolha dos trabalhadores livres, que agora podiam definir onde queriam trabalhar. Os movimentos migratórios no país foram grandes, especificamente nas regiões mais bem capitalizadas, como o Sudeste. 
Segundo Cantelli (2007), em meio a todo esse fluxo migratório estavam às mulheres, cuja mão de obra era empregada em larga escala no início da industrialização, mais especificamente nos ramos de menor mecanização.

Os trabalhos de agulha eram tradicionalmente realizados no domicílio das costureiras e bordadeiras. No caso da indústria de sacaria para o café, utilizou-se a costura domiciliar desde o século XIX, quando as telas ainda eram importadas pelo comissariado nas principais cidades portuárias, prática que se manteve mesmo após a implantação da indústria de fiação e tecelagem de juta. Há registros de que a costura à mão persistiu pelo menos até 1924, sendo, a partir de então, gradativamente substituída pela costura à máquina (CANTELLI, 2007, p.).

Neste sentido, Calil (2007) afirma que a elite dominante na época foi responsável pela implementação da proclamação da república em 1889, preconizando suas ações com base em pensamentos liberais, onde a influência do Estado deveria ser a mínima possível, sem interferir no equilíbrio de forças das leis de mercado, que regular-se-ia por leis próprias.

O papel da mulher no surgimento das leis relativas ao trabalho é de extrema importância, tendo em vista que foi diante da exploração das mesmas que o Estado se sensibilizou e viu a necessidade de intervir. As primeiras leis trabalhistas que surgiram referem-se a alguns direitos do trabalho das mulheres, e muitos desses destes foram conquistados e alguns deles beneficiaram aos homens, assim como outros geraram, indiretamente, discriminações contra a mulher.

\subsection{A MULHER DO SÉCULO XXI}

Em princípio o que podemos chamar de primeiro passo na criação da norma de proteção ao trabalho da mulher foi o nascimento do projeto do código de trabalho, em 1912, que apresentava, dentre outras coisas, alguma legislação específica do trabalho da mulher, tais como a sua liberdade para obtenção de emprego, independentemente 
de autorização do marido, jornada diária limitada a 8 horas, licença de 15 a 25 dias antes do parto e até 25 dias após, e percepção de 1/3 do salário no primeiro período e metade do segundo.

Ressalta-se que, apesar da mudança no modelo político-econômico e social, o país continuou em crescimento até o início dos anos 80, quando nesta década mergulhou numa profunda recessão gerada pela falência no antigo modelo escolhido pelo governo militar. A recessão intensa e aumento da inflação foram os principais fatos econômicos vivenciados naquela época, prejudicando principalmente a camada mais pobre da população e aumentando mais ainda a desigualdade socioeconômica no país, obrigando as mulheres a ingressarem definitivamente no mercado de trabalho em prol da sua sobrevivência e da sua família (FONSECA, 2004).

A recessão econômica e, consequentemente, o achatamento da renda, obrigou as mulheres a sair em busca de trabalho para complementar a renda familiar, reiterando a ideia de que a crise econômica foi o impulso final que as mulheres estavam precisando para abrir mão de um trabalho apenas no lar e sair em busca de novos postos de trabalho que Ihes garantissem a sobrevivência.

Nesta baila, destaca-se que outro fator preponderante na década de 80 foi o aumento do número de postos de trabalho no setor de comércio e prestação de serviços por conta da forte estagnação da economia. Em tais áreas, as mulheres tiveram inclusive mais oportunidades de emprego.

Contudo, nas indústrias, muitas vezes as mulheres não tinham a mesma chance devido ao protecionismo das leis, que as impediam de trabalhar em ambientes insalubres ou com maquinários pesados. Entretanto, com o advento das vagas no setor terciário, foi mais propício a elas a conquista de uma vaga de trabalho, em atividades em que poderiam desempenhar muito bem, e em muitas vezes até mesmo melhor do que homens.

Em 1943, obtivemos outro avanço na edição de normas protetivas à mulher: a promulgação da CLT, conhecida Consolidação das Leis Trabalhistas (BRASIL, 1943), 
consolidando todas as matérias relativas ao trabalho, dentre elas o da mulher. A primeira alteração foi em 1944, quando foi admitido o trabalho noturno da mulher em algumas atividades, desde que ela seja maior de 18 anos.

\subsection{EFEITOS DA PÓS-MODERNIDADE PARA A MULHER NO DIREITO DO TRABALHO}

Calil (2007) delimita a evolução dos direitos do trabalho da mulher em três grandes fases, ou, como ela denomina, ondas de transição. Concernente mencionar que atualmente, pode-se dizer que se vive a fase promocional do direito das mulheres. Há uma busca incessante pela igualdade entre os gêneros. Igualdade esta que se baseia na busca do tratamento diferenciado apenas naquelas situações em que as diferenças biológicas e de tratamento exigirem, e não nas discriminações arbitrárias infundadas, que todos sabem que ainda existe no mundo do trabalho atual.

Segundo Samara (2003), é notável o acréscimo representativo do número de mulheres inseridas no mercado de trabalho atual, inclusive com a conquista de cargos de chefias ou até outros cargos até então inimagináveis, sob o ponto de vista de um contexto histórico, de que pudessem ser confiados às mulheres, como é o caso das gerentes de banco, engenheiras, motoristas, mecânicas etc.

O setor de serviços concentra um grande número de mulheres trabalhadoras, sendo também, por vezes, menos exigente em qualificação em comparação aos demais. É fato que apesar de ter havido grandes avanços no mercado de trabalho dos últimos tempos, a desigualdade entre homens e mulheres ainda persiste de forma significativa.

\section{OS DIREITOS DO TRABALHO DA MULHER NA ATUALIDADE}

Para as relações de direito, principalmente no trabalho da mulher na atualidade, passaremos a discutir sobre o salário da mulher, as proteções inerentes, e as melhorias neste século XXI. 


\subsection{DO SALÁRIO DA MULHER}

No Art. $7^{\circ}$ da Constituição Federal (BRASIL, 1988), assim como no Art. 5ำ da CLT (BRASIL, 1943) está expressa a proibição de diferença de salarial, de exercício de funções e de critério de admissão por motivo de sexo, idade, cor ou estado civil. Conforme o exposto e sob um contexto histórico, pode-se observar que o trabalho da mulher sempre teve um menor valor do que o do homem. Seja porque produziam menos no início da industrialização, ou porque trabalhavam com a produção dos bens de menor valor no mercado, ou porque trabalhavam em empregos que exigiam menor qualificação, ou porque tinham uma jornada de trabalho menor, ou simplesmente porque possuíam uma menor capacidade de se organizarem em sindicatos e lutarem por seus direitos. $O$ fato é que tais diferenças salariais ainda persistem até hoje.

\subsection{DA DURAÇÃO DO TRABALHO DA MULHER}

Ressalta-se que a jornada de trabalho da mulher é igual à dos homens. Ou seja, 8 horas diárias e 44 horas semanais, exceto nos casos para os quais for fixada duração inferior, conforme preceitua o Art. 373 da CLT e o Art. 7º, inciso XIII da Constituição Federal (BRASIL, 1988).

\subsection{DO REPOUSO NO DOMINGO}

Destaca-se que assim como no caso do trabalho masculino, o ideal é que o repouso semanal remunerado seja preferencialmente aos domingos, o que pode não necessariamente ocorrer. Entretanto, no caso das mulheres, se elas optarem por qualquer outro dia que não seja o domingo, é obrigatória a criação de uma escala de revezamento quinzenal, para que, pelo menos de quinze em quinze dias, o repouso semanal remunerado coincida com o domingo. Tal determinação de criação da escala de revezamento está expressa no Art. 386 da Consolidação das Leis do Trabalho (BRASIL, 1943). 


\subsection{DO TRABALHO NOTURNO}

É necessário mencionar que atualmente, não há mais proibição do trabalho noturno pela mulher. A Lei 7.855 (BRASIL, 1989) revogou os artigos 379 e 380 da CLT que tratavam desta questão. As regras são as mesmas para os homens e mulheres.

\subsection{DAS CONDIÇÕES DE TRABALHO}

Ressalta-se que o Artigo 389 da CLT (BRASIL, 1943) determina as condições básicas para prestação do serviço nas mínimas condições exigidas para as mulheres. A existência de um local de trabalho em condições mínimas de existência com higiene, limpeza, iluminação, recursos de proteção individual e estrutura física adequada é condição sine qua non para o efetivo exercício da prestação laboral, independente do gênero da pessoa.

\subsection{DO CASAMENTO DA EMPREGADA}

Destaca-se o artigo 391 da CLT (BRASIL, 1943) em que está determinada a proibição de qualquer conduta de discriminação, constituindo justo motivo para rescisão do contrato de trabalho ao fato da mulher ter contraído matrimônio ou encontrar-se em estado de gravidez. A mesma proibição prevalece nos casos do empregador utilizarse desses argumentos como critério para não contratação das mulheres.

\subsection{DA EMPREGADA GESTANTE}

O texto constitucional de 1988, em seu Art. $7^{\circ}$, XVIII, bem como a CLT, em seu Art. 392, concede como direito fundamental, o afastamento de cento e vinte dias da gestante, com garantia de seu emprego e do salário correspondente.

Destaca-se que nesse período, cujo afastamento é compulsório, interrompe-se o contrato de trabalho e a remuneração devida à empregada, ou seja, os salários integrais constituem o que se denomina salário-maternidade, benefício de natureza previdenciária, regulamentado pela Lei n. 8.213/91 (BRASIL, 1991). 


\subsection{DO PERÍODO DE AMAMENTAÇÃO}

Destaca-se que o artigo 396 da CLT concede à mulher a dois descansos especiais, de meia hora cada um, para amamentar o filho até que ele complete seis meses de vida. A Lei concede também uma dilatação desse prazo de seis meses, caso a saúde do filho exigir.

Pertinente mencionar que há ainda a obrigação dos estabelecimentos com no mínimo 30 mulheres e todas com idade acima de 16 anos, de propiciarem um local adequado onde as empregadas poderão deixar seus filhos durante o período de amamentação. Tal local deverá conter no mínimo um berçário, uma saleta de amamentação, uma cozinha dietética e uma instalação sanitária.

\section{CONSIDERAÇÕES FINAIS}

No decorrer do presente artigo pôde-se evidenciar que o trabalho da mulher esteve presente em todas as épocas da história da humanidade e que o processo de industrialização representou uma alavanca no qualitativo de mão-de-obra exigida para o trabalho, abrindo espaço para a atuação das mulheres, mas que, por outro lado, propiciou a disseminação de várias formas de exploração de seu trabalho, e de diferenciações que, infelizmente, ainda persistem mesmo nos tempos atuais. Ressalta-se que, o passado citado foi uma época de fortes questionamentos a respeito do papel da mulher na sociedade, sendo elas vítimas de duras críticas, incluso sua moral e valor de seu trabalho dentro e fora de casa.

Após a leitura de bibliografia citada, observou-se que todo o trilhar da história demonstra-nos que o universo do trabalho feminino sempre foi marcado por lutas e conquistas, alternadas com comportamentos de submissão e resistência. Muitas das lutas guarnecidas pelas mulheres ofereceram subsídios que resultaram em leis trabalhistas que propiciaram a melhoria das condições de toda uma classe operária. E para tal, a atuação do Estado foi e é imprescindível, na medida em que pode viabilizar as ações afirmativas bem como pode criar formas de efetivá-las, buscando 
a erradicação da discriminação e criando oportunidades de trabalho para ambos os sexos.

Destaca-se que foram qualificados os principais direitos do trabalho da mulher nos tempos atuais, frutos de uma evolução legal, cujo código principal norteador de tais direitos foi a Constituição Federal de 1988 e suas alterações posteriores. Para que isso aconteça, é necessário que haja uma transformação de valores, onde as mulheres poderão ser libertadas de um estereótipo que se perfaz por anos a fio, de um modelo submisso, frágil, e representativo do pecado original, que foi impregnado inclusive pela própria Igreja em tempos antigos.

Certas diferenças biológicas hão de sempre existir, contudo, tais diferenças não podem servir de justificativa para a estagnação de conceitos culturais e a impregnação do preconceito na sua forma mais vil, que é o de atrelar tais diferenças biológicas e emocionais à incapacidade de desenvolver trabalhos, quaisquer que sejam e de evoluir com os mesmos. Por fim, salienta-se que tudo gira em torno de um único pensamento, que é o de que é na mulher que a vida começa, e é com ela que a vida e a sociedade vão se desenvolver.

Conclui-se que, no dia em que a humanidade refletir sobre, e o Estado propiciar não apenas leis que as amparem, mas mecanismos de controle e punição dos que as descumprem, fazendo cumprir-se a justiça verdadeiramente, o mundo do trabalho será melhor para ambos os gêneros, e só então poderá se sonhar com a nação igualitária, tão preconizada no Art. $5^{0}$ da nossa Carta Magna, mas tão pouco vivenciada na nossa realidade histórica.

\section{REFERÊNCIAS BIBLIOGRÁFICAS}

BRASIL. CLT - Consolidação das Leis do Trabalho. Disponível em: http://www.planalto.gov.br/ccivil_03/decreto-lei/del5452.htm. Acesso em 07 de julho de 2019. 
Constituição da Republica Federativa do Brasil. Disponível em: http://www.planalto.gov.br/ccivil_03/constituicao/constituicao.htm. Acesso em 07 de julho de 2019.

$$
\text { Lei 7.855/1989. Disponível em: }
$$

http://www.planalto.gov.br/ccivil_03/leis/L7855.htm. Acesso em 07 de julho de 2019.

$$
\text { Lei 8213/1991. Disponível em: }
$$

http://www.planalto.gov.br/ccivil_03/leis//8213cons.htm. Acesso em 07 de julho de 2019.

CALIL, L. E. S. Direito do Trabalho da Mulher: A questão da desigualdade jurídica ante a desigualdade fática. São Paulo: Ltr, 2007.

CANTELLI, P. O. O trabalho feminino no divã: dominação e discriminação. São Paulo: Ltr, 2007.

FONSECA, C. Ser mulher, mãe e pobre, in História das mulheres no Brasil, São Paulo: Contexto, 2004.

GOMES, O, GOTTSCHALK, E. Curso de direito do trabalho. Rio de Janeiro: Forense, 2005.

NASCIMENTO, A. M. História do Trabalho, do direito do trabalho e da justiça do trabalho. São Paulo: LTr, 2003.

RODRIGUES PINTO, J. A. Curso de direito individual do trabalho: noções fundamentais de direito do trabalho, sujeitos e Institutos do direito individual. São Paulo: LTr, 2006.

SAMARA, E. de. M. As mulheres, o poder e a família: São Paulo, século XIX, São Paulo, 2003.

SILVA, R. P. E. O mercado de trabalho humano. São Paulo: LTr, 2006. 
SUSSEKIND, A. Instituições de direito do trabalho. São Paulo: LTr, 2003.

YANNOULAS, S. C. Dossiê: políticas públicas e relações de gênero no mercado de trabalho. Brasília, 2007. Disponível em: http://cfemea.org.br/publicacoes.asp. Acesso em 07 de julho de 2019.

Enviado: Janeiro, 2019.

Aprovado: Agosto, 2019. 